\title{
OLHANDO E VIVENDO GRUPOS - REFLEXÕES SOBRE UMA PRÁTICA
}

\section{Observing and experiencing groups - reflections on a practice}

\author{
Nedio Antonio Seminotti ${ }^{1}$ \\ Helena Beatriz Kochenborger Scarparo ${ }^{2}$ \\ Maria Lúcia Andreoli de Moraes ${ }^{3}$ \\ Miriam Alves ${ }^{4}$
}

\section{Resumo}

O artigo que é aqui apresentado põe em discussão questões relativas a fenômenos presentes nos pequenos grupos. O texto aborda processos dialógicos gerados pela interlocução entre alunos e professores de disciplinas do curso de graduação da Faculdade de Psicologia da Pontifícia Universidade Católica do Rio Grande do Sul e integrantes de um grupo de pesquisa do Programa de Pós-Graduação da mesma instituição. A partir do relato de práticas efetivadas nas disciplinas de Psicologia dos Grupos de Psicologia Comunitária e do trabalho desenvolvido no referido grupo de pesquisa, foi possível refletir amplamente sobre os fenômenos grupais e sobre a produção de saberes acerca dessa temática. Para tanto, foram utilizados os relatos de sessões terapêuticas grupais de egressos de um hospital psiquiátrico de Porto Alegre. Esse material foi analisado e discutido pelo grupo de trabalho acadêmico. A associação entre os processos e organizações do grupo terapêutico estudado e as diferentes perspectivas que emergiam durante as discussões na academia suscitou problematizações quanto aos fenômenos produzidos e experimentados no grupo de trabalho cotejados com os do grupo terapêutico relatado pelos estudantes. Como decorrência, discutiu-se as formas de pensar, pesquisar, conhecer e socializar saberes sobre grupos. Esse processo reflexivo teve como apoio teónico predominante a perspectiva sistêmica proposta por Edgar Morin.

Palavras-chave: Pequenos grupos; Produção de saberes; Interações sistêmicas.

1 Psicólogo, Doutor em Psicologia pela Universidade Autônoma de Madri, Coordenador do Grupo de Pesquisa "Processos e Organizações dos Pequenos Grupos" do PPGPsicologia - PUCRS.

2 Psicóloga e Doutora em Psicologia pela PUCRS.

3 Psicóloga e Doutora em Psicologia pela PUCRS.

4 Educadora Física Especialista em Saúde Mental Coletiva. Mestre em Psicologia Social e da Personalidade pela PUCRS. Endereço para contato: Av. Ipiranga, 6681 Caixa Postal 1429 - 90619-900 - Porto Alegre-RS

E-mail: nedios@pucrs.br 


\section{Abstract}

This article discusses some issues related to phenomena that are characteristic of small groups. Our study tackles dialogical processes as generated in the interlocution between students and teachers from the undergraduate course in Psychology - School of Psychology, the Pontifical Catholic University of Rio Grande do Sul (PUCRS, Brazil) and members of a research group from the same institution's Postgraduate Program in Psychology. From reports on the practices carried out in the disciplines Group Psychology and Community Psychology, and from the work developed by the above-mentioned research group, we wanted to be able to reflect on group phenomena and on the production of knowledge about such phenomena. Bearing this in mind, reports from group-therapy sessions were used, the group studied comprising former patients of a psychiatric hospital in Porto Alegre, RS, Brazil. This material was analyzed and discussed by the academicwork group. The association between (1) the processes and modes of organization within the group-intherapy studied and (2) the various points of view that emerged during the discussions within the academic group resulted in problematic questions regarding the phenomena produced and experienced in the academic-work group when compared to those of the in-therapy group as reported by the students. As a result, manners of thinking about what one knows about groups were discussed, as well as ways of getting research done on group dynamics, gathering information and making this information collective when it comes to amassing knowledge on how groups function. This process of reflecting on such issues had as its main theoretical frame the systemic approach, as suggested by Edgar Morin (falta ano da referência bibliográfica).

Keywords: Small groups; Production of knowledge; Systemic interactions.

\section{Introdução}

"O complexo surge como impossibilidade de simplificar lá onde a desordem e a incerteza perturbam a vontade do conhecimento, lá onde a unidade complexa se desintegra se a reduzirmos a seus elementos, lá onde se perdem a distinção e a clareza nas causalidades e nas identidades, lá onde as antinomias fazem divagar o curso do raciocínio, lá onde o sujeito observador surpreende seu próprio rosto no objeto de sua observação" (Morin, 2000, p.132)

O presente artigo aborda uma experiência desenvolvida durante a realização de um trabalho teórico-prático efetivado na articulação entre a academia e um grande hospital de atendimento aos usuários do Sistema Único de Saúde de Porto Alegre.

Nesta experiência, estudantes das disciplinas de Psicologia Comunitária e Psicologia dos Grupos do curso de graduação em psicologia observaram e relataram 0 atendimento psiquiátrico grupal que era oferecido pelo Hospital aos usuários egressos. Tal atendimento consistia-se em encontros semanais coordenados por um integrante da equipe psiquiátrica do referido hospital.

Inicialmente, as observações eram relatadas e discutidas em reuniões das quais participavam integrantes do grupo de pesquisa "Proces- so e organizações dos Pequenos Grupos" e os professores e os alunos das disciplinas da graduação envolvidas. Assim, o grupo de pesquisadores foi composto por quatro psicólogas, um psicólogo, uma médica veterinária, uma educadora física, duas alunas e um aluno do curso de graduação em psicologia. Os participantes dessas reuniões discutiam os movimentos e os significados produzidos no grupo de egressos, na tentativa de compreendê-los, e contribuir com o processo terapêuticocomunitário proposto pelo Hospital.

No decorrer dos debates, emergiram questões relativas ao próprio grupo de discussão nas quais era evidente a pluralidade de enfoques, sentidos, posicionamentos e movimentos em relação ao material examinado. Tais questões provocavam reflexões que direcionaram o olhar dos pesquisadores para fenômenos decorrentes do pensar coletivamente e implicar-se com a experiência de saber-se um grupo pensando outro grupo. A singularidade dos pressupostos teóricos dos pesquisadores, seus recortes temáticos e seus modos particulares de analisar os conteúdos dos relatos tiveram papel fundamental na compreensão dos fenômenos grupais observados. Evidenciouse uma rede de significados engendrada a partir do exame coletivo dos relatos e das reflexões decorrentes das discussões e explicitação de diferentes posicionamentos quanto ao conteúdo analisado. Como decorrência, houve uma reorganização de significados num conjunto integrado de dois 
planos: o grupo de egressos desenvolvido no Hospital e o grupo de discussão efetivado na Academia. Esse processo trouxe desdobramentos para a tarefa proposta preliminarmente para além da análise do material empírico coletado. Passamos a examinar a sucessão de mudanças no movimento dialógico estabelecido desde as múltiplas lógicas dos sujeitos dos grupos das duas instituições diretamente envolvidas.

Começamos, então, a gravar e transcrever as narrativas do "grupo que pensava o grupo de egressos". Os encontros produziram outro material empírico, que vem sendo examinado e, pelo qual, elaboramos o presente artigo.

O desejo de produzir conhecimentos que integrassem diferentes perspectivas em movimento apoiou-se no conceito de complexidade proposto por Morin, o qual se consistiu num interesse unânime entre os componentes do grupo de discussão. Inicialmente, com foco no grupo do Hospital, o grupo pautou suas discussões em torno de noções como organização-desorganização, normal-patológico e público-privado dos usuários. O modo de situar-se no grupo tinha como base o estabelecimento de semelhanças e diferenças entre os debatedores. Essas se evidenciavam na maneira peculiar de cada um pensar e abordar grupos, na escolha de temas e exemplos para associar à discussão, nas formas de questionar, problematizar e expressar especificidades. Tratava-se de ressignificar processos de construção teóricoprática. As discussões preliminares desta experiência são relatadas a seguir.

\section{0 diálogo de sujeitos com suas lógicas sobre outras lógicas}

\begin{abstract}
"Surgem as diferenças e as pessoas saem do anonimato, o que possibilita a pessoa expressar sua opinião. No grupo as relações se tornam mais verdadeiras, autên ticas e é possível o convívio das diferenças." (Estudante participante do grupo)
\end{abstract}

O grupo, método para encaminhar soluções à vida, lugar de produção de sujeitos e modo de convivência humana, é um convite ao colóquio, ao estabelecimento de imagens, idéias e argumentos que nos mostram o outro, produzem 0 outro e a nós mesmos numa dimensão até então desconhecida. Berenstein (2001) afirmou que a relação com o outro suplementa o sujeito, o faz ir além. Por isso, o encontro entre sujeitos e a estranheza provocada por essa experiência não pode ser totalmente representada. Nessa mesma perspectiva se situa Morin (2002) com sua noção de acontecimento que designa o singular, o acidental e certo ordenamento que dá visibilidade aos processos que emergem dos encontros entre sujeitos. Designa ordenamentos das interações sistêmicas que, por sua vez, geram desorganizações e outras organizações no sistema. Nessa noção há também a idéia de irreversibilidade temporal, atualização e singularidade do processo. A saber, no acontecer do grupo produzem-se outras configurações caracterizadas por movimentos de organização-desorganização-reorganização.

No caso do presente estudo, o material empírico proveniente do conjunto do Hospital mostrou que, no momento em que se possibilita 0 olhar do outro, atinge-se um modo de relação que transcende a dicotomia das diferenças e semelhanças. Os participantes de uma associação passam a se perceber como sujeitos diversos, podendo expandir a explicitação de seus posicionamentos, suas apresentações como sujeitos que têm suas lógicas particulares e que compõem uma perspectiva dialógica (Berenstein, 2001; Morin, 2002). Desse modo, no grupo da academia produziram-se outros sujeitos, outros modos de ser outros saberes e, como decorrência, e outros processos de grupo.

Pode-se dizer, metaforicamente, que aconteceram mudanças paradigmáticas no conjunto. Os objetivos originais eram de analisar o material advindo do grupo terapêutico a partir da relação do sujeito pesquisador com seu objeto de estudo. No entanto, no decorrer da experiência, passamos a problematizar as relações entre os sujeitos do grupo de discussão e os de egressos considerando a complexidade da rede de relações e significados presentes no exame dos fenômenos grupais.

Essa constatação corrobora a afirmação de Guareschi (1990) de que o ser humano é relativo porque se produz nas relações. No encontro com outros sujeitos, pudemos relativizar modos de ser, pressupostos teóricos, discursos, práticas e sentimentos. E na esfera das relações que reencontramos questões filosóficas fundamentais e forjamos espaços de discutibilidade que transcendem os dogmas e disciplinas da ciência clássica, num 
contínuo processo de desenvolvimento das aptidões auto-reflexivas dos sujeitos e dos grupos em relação (Morin, 2002). Assim, o grupo da Academia passou a ser concebido e a constituir-se como "sistema-grupo", o que implica uma visão multidimensional. Assim, leva-se em conta os diferentes sistemas de idéias de cada participante, estabelecendo movimentos no espaço de convivência entre os sujeitos que se produzem mutuamente e que recursivamente produzem esse espaço. (Seminotti, Borges \& Cruz 2004; Alves, 2005).

\section{A alteridade e as dicotomias "normal-patológico" e "público-privado"}

A Psicologia Social Crítica, em suas discussões contemporâneas, vem trazendo à tona a questão da alteridade por considerá-la essencial do ponto de vista teórico e no plano das práticas sociais. A discussão sobre alteridade surge exatamente da consideração pela existência do outro enquanto outro, diferente de mim mesmo tanto em suas concepções filosóficas e ideológicas, como em seu agir no mundo. Para Guareschi (1990, 2004), definir alteridade principia pela explicitação do conceito de relação. Considera que relação é algo que se apresenta pela presença de um em posição relativa ao outro, isto é, um se define em referência ao outro. Portanto, a noção de relação não é absoluta, não constitui a natureza de um ser sozinho, senão que se aplica à interação que circula entre os dois sujeitos considerados. Além disso, a noção de relação implica na constatação de que aquilo que se passa entre os sujeitos é sempre incompleto, há sempre algo mais a ser construído ou desconstruído, um estado sempre móvel, constantemente exposto ao encontro e desencontro das singularidades.

A alteridade não se resume ao simples reconhecimento do eu e da existência do outro, mas supõe necessariamente a consideração pela sua legitimidade enquanto sujeito expressivo, portador e transformador de idéias, modos de ser e projetos que lhe são próprios (Jovchelovitch, 1999).

No decorrer das discussões do grupo da Academia, as dicotomias estabelecidas entre os conceitos de normal e patológico denotaram marcantes conexões com as idéias de público e privado, especialmente quando associadas às reflexões teóricas sobre alteridade.
De acordo com os dados produzidos no grupo do Hospital, o âmbito privado evidenciouse como espaço que torna possível algumas vivências de recolhimento, contato e expressão mais efetiva com o modo de ser peculiar de cada sujeito: configurado como lugar de maior intimidade. Relatam os usuários que nesse espaço são tolerados alguns comportamentos não aceitos e considerados patológicos na esfera pública. É o caso das manifestações de agressividade, irritação ou descuido com a própria higiene ou aparência. Na esfera pública, formalizam-se julgamentos mais rigorosos de acordo com padrões socialmente instituídos de adequação e inadequação aos parâmetros de normalidade. Esses parâmetros também servem para estabelecer práticas de inclusão-exclusão a partir da categorização dos sujeitos como "normais" ou "patológicos".

A aprendizagem relativa à categorização "normal" e "patológico" está presente no âmbito da formação, na medida em que, tradicionalmente, os currículos dos cursos voltados para a saúde mental prescrevem disciplinas com ênfase na descrição, reconhecimento e categorização de sintomas e quadros diagnósticos. Nesta perspectiva, o grupo da Academia problematizou os currículos dos cursos de formação de psicólogos, muitos dos quais priorizam uma abordagem apoiada na nosografia e, conseqüentemente, na lógica da doença. Tendo em vista essa reflexão crítica sobre as práticas psicológicas e o contexto no qual elas se inscrevem, podemos afirmar que tal perspectiva apóiase num conceito abstrato e importuno de sujeito que impede a construção de práticas sociais emancipatórias e, ao mesmo tempo, corrobora uma lógica de mercado cruel e mantenedora de lugares de dominação e exclusão.

Na esfera pública, há um número incalculável de interações e inter-relações. Habitar esse espaço complexo e significá-lo potencializa relações dialógicas. Assim, podemos afirmar que na esfera pública a diversidade tem maior visibilidade e que a relação dialógica se estabelece intensamente nesse espaço. $\mathrm{O}$ auto-reconhecimento se dá pelo enfrentamento da alteridade. Considerar tal idéia é condição sine qua non para a compreensão/construção das singularidades.

A articulação entre esfera pública e o espaço intragrupo pode ser estendida para as relações intergrupais. Desde esse pressuposto, os sujeitos do grupo de egressos são estranhos aos su- 
jeitos do grupo de discussão e deste como totalidade. Entretanto, as reflexões geradas pela constatação da diversidade e das semelhanças tornou explícita e complexa a rede de relações sociais que envolve a problematização/contato com as dicotomias normal-patológico e público-privado.

Ao conceber o ser humano como ser em relação, como propõe Guareschi (1990), afirmamos sua subjetividade como um devir, ou seja, a subjetividade é produzida continuamente nos encontros com os outros. Como decorrência, os diferentes integrantes dos grupos estudados - da Academia e do Hospital - se constituem nas relações com outros sujeitos pela alteridade que se presentifica. Esses processos constituem os grupos e os sujeitos que, recursivamente, organizam e desorganizam suas relações e, em decorrência disso, os devires se põem em evidência.

A discussão do tema da alteridade neste processo que denominamos de "grupo sobre grupo" é central. Isso porque a constatação da alteridade foi condição essencial para que o grupo refletisse sobre si mesmo na perspectiva da complexidade. Tal tarefa foi tecida na interconexão e emergiu das relações estabelecidas entre os diferentes sujeitos implicados nesses grupos, ou seja, os participantes do grupo da Academia e os do Hospital. Nessa situação, o grupo do Hospital constituiu, para o da Academia, a emergência da alteridade. Por outro lado, a explicitação da alteridade mobilizou outras perspectivas de relação e de criação no grupo de discussão. Como decorrência, processou-se uma profícua e complexa rede de efeitos no movimento de reconhecer-se como sistemas em interação, no estudo em foco, um sistema pequeno grupo.

\section{Sistema pequeno grupo na transversa liza ção entre diferentes sistemas de idéias}

Tomar à análise o grupo da Academia, na perspectiva de um sistema pequeno grupo, significa considerar os processos de interações entre os sujeitos e suas organizações e de subjetivações que nele e por eles são produzidos a partir das informações partilhadas, inicialmente, sobre o grupo do Hospital (Alves, 2005).

A tentativa de compreensão do processo de construção de conhecimento que se efeti- vou nessa prática, é entendida como a construção de um sistema de idéias próprio de cada um dos sujeitos e/ou do conjunto deles que operam com múltiplas lógicas (Morin, 2001). Tal construção requer uma visão multidimensional do movimento estabelecido que engloba a heterogeneidade do pequeno grupo, os diferentes sistemas de idéias que o atravessam, as idéias que são engendradas pelo material empírico, seu vir-a-ser aleatório e 0 dos próprios participantes. Cabe ressaltar que, a partir das interações intra e intergrupo/s, inauguram-se espaços de escuta para posicionamentos alternativos.

As interações do grupo da Academia são motivadas por outra ação: o relato da observação do grupo do Hospital. Na experiência relatada, um sistema pequeno grupo de pesquisadores observa e analisa outro sistema pequeno grupo. Não obstante, estas relações intergrupais também ocorrem quando o sistema pequeno grupo de pesquisadores interage com os diferentes sistemas de idéias trazidos por seus participantes. Dentre estes, destacam-se a psicanálise, a reforma psiquiátrica e a teoria da complexidade.

Nesse processo, pôs-se em relevo o devir das idéias e dos sentidos das relações entre os integrantes do grupo. Em seu conjunto, as interações intragrupais produziram organizações e desorganizações nas relações entre participantes. Emergiram processos de organização, desorganização que geraram posicionamentos e sujeitos diversos.

A organização pode ser compreendida como o elo entre os elementos de um sistema. Nas palavras de Morin (2002): “a organização é o que liga um sistema" (p. 278), ou "a organização é aquilo que constitui um sistema a partir de elementos diferentes" (p. 180). Ela permite regular as relações, dar coerência, sentido e estrutura às suas ações e interações como unidades de um conjunto humano (Morin, 2002, p. 265). As pessoas tratam de construir uma auto-organização de forma que as interações entre elas resultem numa ligação que institua a interdependência produtiva, regenerativa, e que respeite e promova a autonomia. Ao mesmo tempo, buscam fazer com que essa auto-organização assegure o respeito às suas singularidades, condição indispensável à vida do pequeno grupo (Seminotti, Borges \& Cruz, 2004).

No sistema pequeno grupo formulado na Academia, as pessoas foram movidas por suas 
maneiras particulares de analisar o conteúdo dos relato s e trataram de constituir uma organização que permitisse interações eficazes. E, com este intuito, o sistema mostrou-se aberto para receber informações de outro sistema, o do grupo do Hospital e para receber informações de diferentes sistemas de idéias representados pelos diferentes integrantes do grupo de discussão. $\mathrm{Ou}$ seja, o conteúdo dos relatos favoreceu constituir organizações generativas, ao mesmo tempo dar continuidade da vida do grupo. Para isso, o sistema mostrou-se aberto e fechado. Aberto para receber informações do sistema grupo do Hospital e para compartilhar informações de diferentes sistemas de idéias representados pelos diferentes integrantes do grupo da Academia. Mostrou-se, ao mesmo tempo, fechado em suas idéias, como fechados estiveram também os sujeitos deste grupo de forma a permitir uma comunicação mínima.

Assim, os sistemas descritos acima se atraem ou se repelem em função dos seus princípios paradigmáticos. São abertos para receber informações do exterior e continuar seu processo de construção de conhecimento. Entretanto, também é um sistema que necessita preservar sua singularidade e sua originalidade. Como decorrência, na perspectiva da complexidade, podemos afirmar que o grupo de discussão também se fechou para alguns sistemas de idéias que se construíram com princípios paradigmáticos diferentes dos seus. Fechou-se para manter a organização do sistema de idéias que vem sendo construído e para preservar uma organização mínima indispensável à vida do grupo de discussão

Embora seu enclausuramento, não consideramos que o grupo de discussão esteja construindo uma doutrina, haja vista que vem buscando a dialógica entre os conceitos e idéias trazidas pelas pessoas, rejeitando apenas aquilo que não é pertinente com seus princípios paradigmáticos, e vem demonstrando flexibilidade e vigor polêmico nas discussões. "A diferença entre doutrina e teoria depende, com freqüência, não das próprias idéias componentes do sistema, mas do fechamento ou da abertura da sua organização" (Morin, 2001, p.164).

Desse modo, o processo de subjetivação constitui-se no vir-a-ser aleatório produzido a partir das interações e organizações do sistema pequeno grupo. Subjetivação que se produz na transversalidade dessa rede de sistemas interdependentes na qual estamos situados. A subjetividade não é o ser, tampouco a essência, a raiz do ser, mas sim, os modos de ser na interação com a outra pessoa, com os outros sistemas. É uma experiência individual e coletiva a um só tempo, ou seja, pressupõe a autonomia e a dependência na interação com o outro para a produção de si. E, neste caso, produção de um sistema de idéias próprio.

Também deve ser considerada a idéia de que o sistema é diferente da soma das partes e que o conjunto humano pode acrescentar ou subtrair potência a cada pessoa. Ou seja, as relações fazem surgir emergentes que retroagem ao nível das partes e estimulam-nas a exprimir suas potencialidades. Ao mesmo tempo pode estabelecer-se um processo de inibição das potencialidades. Neste caso, a organização provoca coerções que restringem potencialidades existentes no sistema grupo. Isso quer dizer que as idéias e práticas que surgiram nesse sistema-grupo não representam a totalidade das idéias das pessoas que dele participam. Muitas idéias, pelo princípio da exclusão (Morin, 2003), foram ignoradas pelo grupo por serem consideradas ameaçadoras à unidade e à vida do grupo naquele momento. Essa noção sugere uma simplificação da complexidade, no entanto, para Morin (2002), a simplificação é parte da complexidade. Talvez estivéssemos numa fase em que um determinismo simplificador, como o apontado por Jodelet (1999), tenha instalado estereótipos e preconceitos em nossas relações. Porém, o sistema grupo da Academia - pôde manter-se relativamente aberto e fechado, o que possibilitou sua sobrevivência e pelo princípio de inclusão manter uma possibilidade de comunicação. $O$ fato do sistema ser ao mesmo tempo aberto e fechado e de operarem simultaneamente os princípios de exclusão e inclusão permitiu a continuidade da vida do grupo e a constante renovação do sistema.

Portanto o "todo é mais que o todo" (Morin, 2002), pois emerge da rede de relações. Na experiência aqui relatada, emergiu a necessidade de refletir teórico-criticamente e problematizar as práticas vivenciadas. A partir de então, estabeleceram-se processos dialógicos que apontaram múltiplos caminhos para outras problematizações. 


\section{Considerações finais}

"Começando a entrar mais fundo nestes escritos, uma das reflexões que buscarei fazer nas linhas seguintes parte de um triplo olhar sobre mim e os grupos. Por quê? Simplesmente porque sou analisado e analisando por duas vezes, a primeira feita pelo grupo sobre grupo e a segunda feita individualmente neste trabalho. Por duas vezes observo e sou observado." (Estudante participante do grupo de discussão)

Ao tecer considerações sobre esse intenso processo vivido, percebemos que o grupo, enquanto modo de estar com os outros, pode ser compreendido como um devir, na medida em que está fundado na geração contínua de relações que o constituem como tal. Essa circunstância confere ao grupo a condição de um sistema aberto e fechado simultaneamente, o que permite sua transformação contínua.

A proposta de discutir o processo e organização do grupo da Academia surgiu a partir da constatação de diferenças, semelhanças, incertezas, preconceitos, estereótipos... A idéia inicial - analisar os conteúdos advindos do grupo de egressos de internação psiquiátrica - apoiava-se na convicção de que o grupo a ser examinado representava o outro, o "fora de nós". O contato com os dados coletados e, provavelmente, a acessibilidade do grupo para a alteridade promoveu contatar com estranhamentos e com a constatação de imbricamentos de sentidos presentes nos dois grupos em foco. Como descreve Morin (2002), o sistema que é aberto e que é composto de relações gera acontecimentos irreversíveis que o modificam e o complexificam. Foi o que ocorreu com o grupo de discussão, que se tornou mais complexo na medida em que se confrontou com a alteridade.

Assim, podemos afirmar que na constatação da complexidade e suas implicações reside a riqueza dos estudos dos movimentos grupais. Poderíamos articular as diferenças presentes nos grupos considerando o quanto elas auxiliavam na problematização de um fenômeno simplesmente. É possível compreender que o conhecimento é sempre parcial e perspectivista, e a partir da incerteza, buscar em um pensamento complexo, espaços de reflexões críticas sobre as práticas sociais que se estabelecem nas redes de relações das quais somos parte.

O "outro" também pode estar em nós, assim como o que atribuímos a ele. $\mathrm{O}$ outro também é estranho a nós, como é estranho algo de nós mesmos. Assim como os participantes do grupo de egressos, também tínhamos dúvidas, conflitos e manifestávamos sofrimentos que, se compreendidos radicalmente dentro da abordagem tradicional da doença mental, poderiam nos colocar no lugar dos "sintomáticos". Com isso, passamos a problematizar conceitos, diagnósticos, categorizações, idéias pré-concebidas e estereótipos. Revigorou-se a idéia de trabalhar com a incerteza (Morin, 2002). Isso porque o "outro" é sempre mais do que podemos compreender ou depreender dele, é alteridade radical por não poder nunca ser totalmente assimilado (Berenstein, 2003).

Relação e relativo são palavras afins (Guareshi,1999). Com essa experiência, o grupo de discussão pôde relativizar e ampliar sua compreensão da complexidade dos sujeitos tecida em conjunto, sempre se produzindo, em um vir-a-ser inconstante. A idéia de Morin (2000, 2003) de ecologia da ação entranha-se neste contexto: uma vez iniciada a ação, essa pode ser desviada de seus fins, pelas interações e retroações que se estabelecem no meio em que é efetuada. As conseqüências últimas da ação são imprevisíveis.

O momento da apresentação dessas idéias é uma possibilidade de troca e o estabelecimento de relações com outras pessoas. Como afirma Bauleo (1989), a inclusão do leitor provoca 0 alargamento de possibilidades de entendimento de uma escrita. Essa condição sempre é enriquecedora e complexa, tecida em conjunto e pode ser considerada um acontecimento pelo seu caráter modificador.

\section{Agradecimentos}

Agradecemos ao psiquiatra Luiz Ziegelman, Mestre em Psicologia Social, à psicóloga Cassandra Cardoso, Mestre em Psicologia Social, e aos acadêmicos Leonardo Martins Costa Garavello, Luiza Barros e Fernanda Leite, pela inestimável colaboração para a elaboração do presente estudo. 


\section{Referências}

Alves, M.C. (2005). Produção e organização do sistema pequeno grupo "oficina de capoeira": um estudo no contexto da reforma psiquiátrica. Porto Alegre. Dissertação Mestrado em Psicologia Social e da Personalidade, Pontifícia Universidade Católica do Rio Grande do Sul, Porto Alegre.

Bauleo, A. (1989). Prólogo de uno incluído como lector en el texto El campo grupal: notas para una genealogía. In: Fernandez, Ana Maria. El campo grupal. Nueva Vision: Buenos Aires.

Berenstein, I. (2003). Reflexões sobre uma psicanálise do vínculo. In Green, A (org). Psicanálise Contemporânea: Revista Francesa de Psicanálise. (pp.183-198). Rio de Janeiro: Imago.

Berenstein, I. (2001). El sujeto y el otro: De la ausencia a la presencia. Buenos Aires: Paidós.

Guarechi, P. (1990). Alteridade e relação: uma perspectiva crítica. In Arruda, A. (org). Representando a alteridade. Petrópolis: Vozes.

Guareschi, P. (1999). Pressupostos psicosso ciais da exclusão: competitividade e culpabilização. In Sawaia, B. (org). As artimanhas da exclusa: Análise psicossocial e ética da desigualdade social. Petrópolis: Vozes.
Guareschi, P. (2004). Psicologia Social Crítica. Porto Alegre: EDIPUCRS.

Jodelet, D. (1999). Os processos psicossociais da Exclusão. In Sawaia, B. (org). As artimanhas da exclusão: Análise psicossocial e ética da desigualdade social. Petrópolis: Vozes.

Morin, E., \& Moigne, J. L. L. (2000). A inteligência da complexidade. São Paulo: Petrópolis.

Morin, E. (2001). O Método: 4 As idéias: Habitat, vida, costumes, organização. Porto Alegre: Sulina.

Morin, E. (2002). Ciência com Consciência. Rio de Janeiro: Bertrand Brasil.

Morin, E. (2003). A cabeça bem feita: repensar a reforma, reformar o pensamento. Rio de Janeiro: Bertrand Brasil.

Seminotti, N., Borges, B., \& Cruz, J. (2004). O pequeno grupo como organizador do ambiente de aprendizagem. Psico USF, 9(2), 181-199.

Recebido em/received in: 04/04/06 Aprovado em/approved: 12/05/06 